University of Montana

ScholarWorks at University of Montana

\title{
Nest Predation Risk and Growth Strategies of Passerine Species: Grow Fast or Develop Traits to Escape Risk?
}

Yi-Ru Cheng

Thomas E. Martin

University of Montana - Missoula, tom.martin@umontana.edu

Follow this and additional works at: https://scholarworks.umt.edu/wildbio_pubs

Part of the Life Sciences Commons

Let us know how access to this document benefits you.

\section{Recommended Citation}

Cheng, Yi-Ru and Martin, Thomas E., "Nest Predation Risk and Growth Strategies of Passerine Species: Grow Fast or Develop Traits to Escape Risk?" (2012). Wildlife Biology Faculty Publications. 28.

https://scholarworks.umt.edu/wildbio_pubs/28

This Article is brought to you for free and open access by the Wildlife Biology at ScholarWorks at University of Montana. It has been accepted for inclusion in Wildlife Biology Faculty Publications by an authorized administrator of ScholarWorks at University of Montana. For more information, please contact scholarworks@mso.umt.edu. 


\title{
Nest Predation Risk and Growth Strategies of Passerine Species: Grow Fast or Develop Traits to Escape Risk?
}

\author{
Yi-Ru Cheng ${ }^{1, \star}$ and Thomas E. Martin ${ }^{2}$ \\ 1. Montana Cooperative Wildlife Research Unit, University of Montana, Missoula, Montana 59812; 2. U.S. Geological Survey Montana \\ Cooperative Wildlife Research Unit, University of Montana, Missoula, Montana 59812
}

Submitted January 30, 2012; Accepted May 27, 2012; Electronically published July 18, 2012

Online enhancement: appendix. Dryad data: http://dx.doi.org/10.5061/dryad.33d6c.

\begin{abstract}
Different body components are thought to trade off in their growth and development rates, but the causes for relative prioritization of any trait remains a critical question. Offspring of species at higher risk of predation might prioritize development of locomotor traits that facilitate escaping risky environments over growth of mass. We tested this possibility in 12 altricial passerine species that differed in their risk of nest predation. We found that rates of growth and development of mass, wings, and endothermy increased with nest predation risk across species. In particular, species with higher nest predation risk exhibited relatively faster growth of wings than of mass, fledged with relatively larger wing sizes and smaller mass, and developed endothermy earlier at relatively smaller mass. This differential development can facilitate both escape from predators and survival outside of the nest environment. Tarsus growth was not differentially prioritized with respect to nest predation risk, and instead all species achieved adult tarsus size by age of fledging. We also tested whether different foraging modes (aerial, arboreal, and ground foragers) might explain the variation of differential growth of locomotor modules, but we found that little residual variation was explained. Our results suggest that differences in nest predation risk among species are associated with relative prioritization of body components to facilitate escape from the risky nest environment.
\end{abstract}

Keywords: differential growth, locomotor, endothermy, nest predation, passerine.

\section{Introduction}

Growth and development reflect rates of size increase and functional maturity, respectively, and are integral components of life-history strategies that have critical consequences for offspring quality, survival, and reproduction (Roff 1992; Arendt 1997; Lindström 1999). Species differ in their relative rates of growth and development of body components, but the environmental sources of selection that might cause this variation remain unclear (Sacher and

* Corresponding author; e-mail: yirucheng@gmail.com.

Am. Nat. 2012. Vol. 180, pp. 285-295. (c) 2012 by The University of Chicago. 0003-0147/2012/18003-53615\$15.00. All rights reserved. DOI: $10.1086 / 667214$
Staffeld 1974; Austin and Ricklefs 1977; O'Connor 1977, 1984; Ricklefs 1979; Klingenberg 1998). Predation of offspring is one ecological factor that exerts strong selection on growth rates of body mass across taxa (Case 1978; Arendt 1997; Remes and Martin 2002; Martin et al. 2011). Faster growth rates of mass from higher predation risk, however, might yield slower or impaired growth and development of locomotor traits, given that growth rate of mass can trade off with development of other body components (Ricklefs 1968, 1979; Arendt 1997). Indeed, faster mass growth in fish and tadpoles causes slower burst swimming speeds (Billerbeck et al. 2001; Arendt 2003). Alternatively, growth of body components that reduce the risk of predation, such as locomotor modules, may be relatively prioritized over mass in species at higher risk of offspring predation. Of course, all body components that are key to escape might simply grow in unison, rather than differentially, in response to predation risk, but these alternatives are untested.

Passerine birds provide a good test system, because nest predation is usually the primary source of offspring mortality and can influence growth rates of mass (Martin 1992, 1995; Bosque and Bosque 1995; Remes and Martin 2002; Martin et al. 2011). As a result, relatively faster development of wings and tarsi can facilitate escape from predators (Dial 2003; Dial et al. 2006, 2008; Jackson et al. 2009; Dial and Jackson 2010) and also allow earlier departure from nests. Thus, species might prioritize growth of locomotor components over mass if nest predation risk is higher (fig. 1). Indeed, a recent experimental study that exposed preovulatory and ovulating females to predator models showed that wing growth was prioritized over body size (Coslovsky and Richner 2011), demonstrating that predation risk can shift growth prioritization of body components within a species. Whether such differential prioritization occurs across species in relation to risk of predation is unknown and is the focus of our study here.

Although we focus on testing the potential role of pre- 

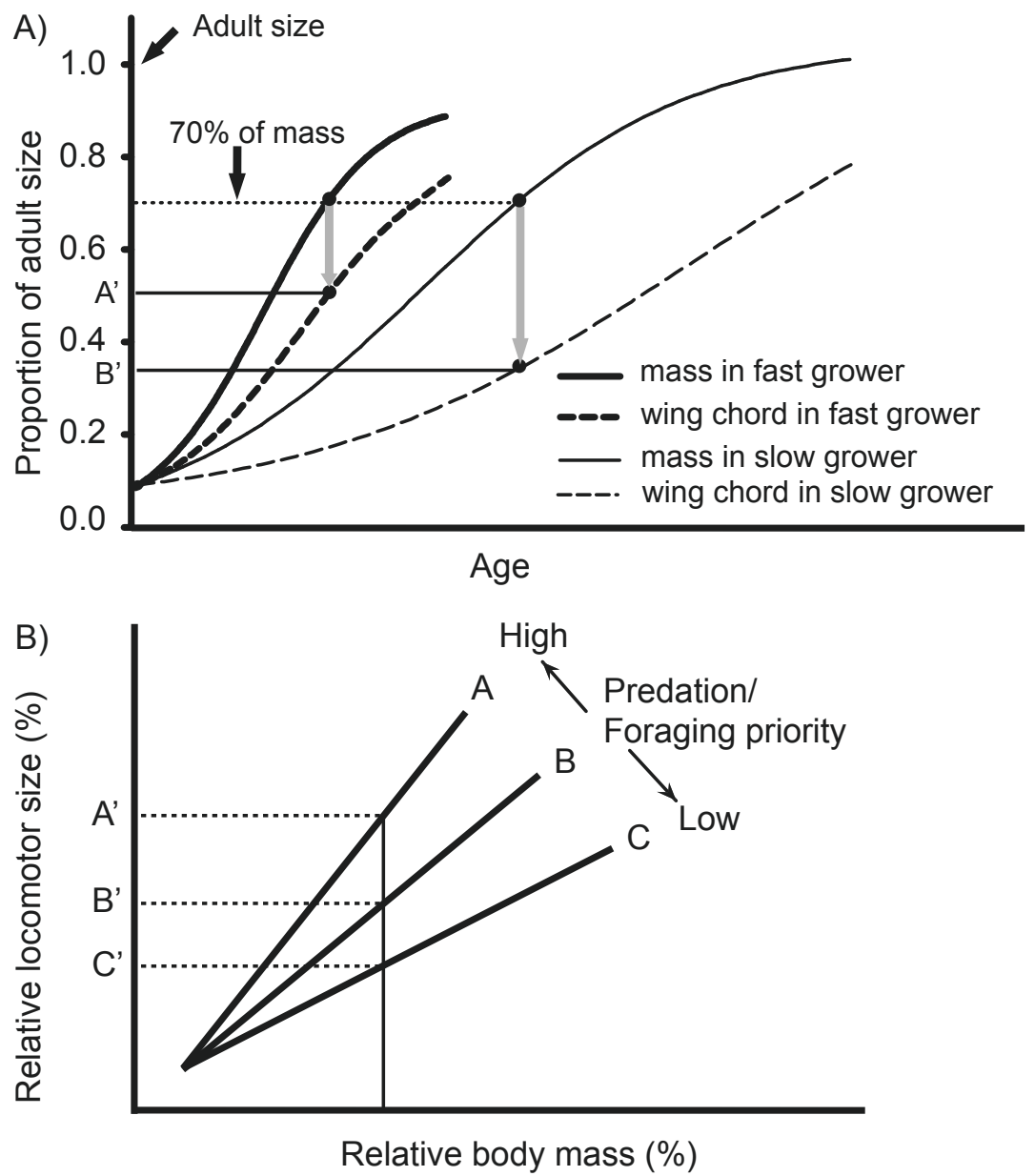

Figure 1: A, Diagram of growth of a locomotor component (demonstrated as wing chord here) and body mass in slow and fast growers. Relative growth of locomotor components (wings and tarsi) among species is provided by comparing them at a constant proportion of adult mass. In this example, compared with a slower-growing species, a species with relatively faster growth rate of the wing chord achieves a larger proportion of adult wing chord when it reaches $70 \%$ of adult mass $\left(\mathrm{A}^{\prime}>\mathrm{B}^{\prime}\right)$. B , Predictions of differential growth of locomotor components and body mass in relation to nest predation or foraging modes. Three lines of A, B, and C were representatives of species with different nest predation risk or foraging modes, where $\mathrm{A}^{\prime}, \mathrm{B}^{\prime}$, and $\mathrm{C}^{\prime}$ were corresponding values of relative locomotor size at a constant relative offspring mass (i.e., relative to adult mass). If nest predation has no influence on the relative growth of locomotor and mass, $\mathrm{A}^{\prime}$, $\mathrm{B}^{\prime}$, and $\mathrm{C}^{\prime}$ should be equal. Otherwise, species with higher nest predation risk or foraging priority (e.g., wings for aerial foragers and tarsi for ground foragers) should have prioritized growth of locomotor components that yield larger relative sizes of these traits at a constant relative offspring mass, as shown in the graph $\left(\mathrm{A}^{\prime}>\mathrm{B}^{\prime}>\mathrm{C}^{\prime}\right)$.

dation in differential growth of locomotor traits and mass, we also explore the possibility that locomotor traits might be prioritized relative to foraging efficiency. Traits that facilitate foraging efficiency once the offspring begin foraging for themselves might grow the fastest and be prioritized over mass to reduce risk of starvation after fledging. We tested this possibility by examining whether clearly different foraging modes and food sources (aerial, arboreal, and ground foragers) might explain differential growth rates of locomotor traits.

Locomotor modules are not the only body components critical to early nest departure. Altricial birds are not homeothermic when they hatch and instead develop endothermy as they grow. They need to thermoregulate on their own to be able to leave the nest and still meet the metabolic demands of locomotion and ability to withstand ambient temperatures alone (Bennett and Ruben 1979). Development of endothermy entails a maintenance cost that could reduce resources allocated to growth and constrain overall growth rates (Ricklefs 1973; Olson 1992), which might yield a trade off between rate of development of endothermy and mass growth rates. Yet, rate of development 
of endothermy was found to positively correlate with rate of mass growth across species of altricial birds in one study (Dunn 1975), such that faster mass growth may facilitate faster development of endothermy. Ultimately, species with higher nest predation risk should develop endothermy at earlier ages to facilitate their ability to leave the nest earlier. Faster development of endothermy might then either trade off with mass growth rate or be facilitated by faster mass growth. These possibilities also remain untested.

We examined differential growth of body components in relation to variation in nest predation risk in 12 coexisting passerine species that represent three major foraging behaviors. Nest predation rates of these species also vary significantly based on robust estimates from longterm (>20-year) studies (Martin et al. 2007, 2011). This variation in nest predation risk among species provides a strong basis to test its potential role in growth strategies. We examined whether species with higher nest predation rates prioritized growth of locomotor modules (e.g., tarsus and wing) and development of endothermy over body mass or if all traits simply grow faster in unison.

\section{Material and Methods \\ Study Area and Species}

We studied 12 coexisting species of passerines in a highelevation $(\sim 2,400 \mathrm{~m})$ ecosystem in north-central Arizona $\left(34^{\circ} \mathrm{N}, 111^{\circ} \mathrm{W}\right.$; table 1$)$. The 12 species represent eight families and 12 genera in Passeriformes. These species use ground, shrub, and cavity nest sites that differ substantially in nest predation risk (Martin and Li 1992; Martin 1995; Fontaine et al. 2007). Study plots were snowmelt drainages where dominant canopy trees were white fir (Abies concolor), Douglas-fir (Pseudotsuga menziesii), ponderosa pine (Pinus ponderosa), and quaking aspen (Populus tremuloides). Understory species included canyon maple (Acer grandidentatum), Gambel's oak (Quercus gambellii), and New Mexican locust (Robinia neomexicana; Martin 2007).

\section{Field Data}

We located and monitored fate of nests from early May to late July during the period 1988-2005 to obtain robust estimates of nest predation rates (Martin et al. 2007, 2011). Nests were monitored every other day to determine hatch dates and fate (Martin and Geupel 1993). Growth rates and development of endothermy were measured from nests studied during 2006-2008; during this period, a total of 80 nests were monitored and 328 nestlings were measured for 12 species. The resulting estimates were nearly identical to estimates from larger and broader samples (Martin et al. 2011), but we use the same nests for growth estimates that we used for endothermy measurements to standardize any potential among-nest variance.

We measured body mass, tarsus length, and wing chord length of nestlings in the afternoon at approximately the same time every other day after hatching. We measured mass using an Acculab PP2060D scale $( \pm 0.001 \mathrm{~g})$ and lengths using Mitotoyu calipers $( \pm 0.01 \mathrm{~mm})$. Tarsus was measured as the length of tarsometatarsal bone, and wing chord was measured as distance from the carpal joint to the tip of the longest primary feather (or feather sheath). We estimated growth rates of mass, tarsus, and wing chord for each species using the logistic growth curve $Y(t)=$

Table 1: Phylogeny, species code, and growth and development estimates for study species

\begin{tabular}{|c|c|c|c|c|c|c|c|c|c|c|}
\hline Common name & Scientific name & Family & $\begin{array}{l}\text { Species } \\
\text { code }\end{array}$ & $\begin{array}{c}\text { No. } \\
\text { nestling }\end{array}$ & $\begin{array}{l}\text { Fledging } \\
\text { age (days) }\end{array}$ & $K_{\mathrm{m}}$ & $K_{\mathrm{t}}$ & $K_{\mathrm{w}}$ & $\begin{array}{c}\text { Age of } \\
\text { endothermy } \\
\text { (days) }\end{array}$ & $\begin{array}{c}\text { Relative } \\
\text { mass at } \\
\text { age of } \\
\text { endothermy }\end{array}$ \\
\hline Cordilleran flycatcher & Empidonax occidentalis & Tyrannidae & COFL & 24 & 15.5 & .483 & .29 & .28 & 9.5 & .96 \\
\hline Warbling vireo & Vireo gilvus & Vireonidae & WAVI & 12 & 13.2 & .540 & .34 & .29 & 9.2 & .89 \\
\hline Mountain chickadee & Parus gambeli & Paridae & $\mathrm{MOCH}$ & 52 & 19.7 & .447 & .34 & .23 & 13.9 & 1.06 \\
\hline Green-tailed towhee & Pipilo chlorurus & Emberizidae & GTTO & 26 & 11.1 & .589 & .42 & .34 & 6.6 & .66 \\
\hline Grey-headed junco & Junco hyemalis & Emberizidae & GHJU & 31 & 11.6 & .545 & .41 & .35 & 7.2 & .73 \\
\hline Red-faced warbler & Cardellina rubrifrons & Parulidae & RFWA & 35 & 11.2 & .576 & .4 & .37 & 8.0 & .93 \\
\hline Virginia's warbler & Oreothlypis virginiae & Parulidae & VIWA & 17 & 10.4 & .605 & .37 & .38 & 8.0 & .90 \\
\hline Western bluebird & Sialia mexicana & Turdidae & WEBL & 14 & 20.0 & .485 & .38 & .22 & 12.8 & .99 \\
\hline American robin & Turdus migratorius & Turdidae & AMRO & 14 & 14.6 & .533 & .38 & .34 & 6.6 & .57 \\
\hline Hermit thrush & Catharus guttatus & Turdidae & HETH & 31 & 12.7 & .570 & .38 & .36 & 7.3 & .75 \\
\hline \multicolumn{11}{|l|}{ White-breasted } \\
\hline nuthatch & Sitta carolinensis & Sittidae & WBNU & 23 & 24.6 & .471 & .33 & .19 & 18.2 & 1.16 \\
\hline House wren & Troglodytes aedon & Troglodytidae & HOWR & 49 & 17.2 & .479 & .35 & .25 & 11.7 & 1.00 \\
\hline
\end{tabular}

Note: Growth rates of mass $\left(K_{\mathrm{m}}\right)$, tarsi $\left(K_{\mathrm{t}}\right)$, wing chords $\left(K_{\mathrm{w}}\right)$, and age of endothermy were estimated from logistic growth curves. Age of endothermy was defined as the day when homeothermic index achieved 0.9 . 
$A /\left[1+e^{-K\left(t-t_{i}\right)}\right]$, where $Y(t)$ is mass, tarsus length, or wing chord length of a nestling at time $t, A$ is the estimated asymptote, $K$ is growth rate, and $t_{i}$ is the inflection point of the logistic curve (Ricklefs 1968). This method is commonly used for growth analysis in birds and provides standardized estimates for comparative studies (Remes̊ and Martin 2002). We estimated the growth rates of mass with data truncated at $70 \%$ of adult mass to account for the problem of overestimation from mass recession and different relative fledging masses among species (Remes̊ and Martin 2002).

We estimated the age of endothermy using the homeothermic index $(H)$. This index was measured in a cold stress experiment every other day after hatching immediately following growth measurements (Dunn 1975; Ricklefs 1987). To reduce the manipulation time, only half of the nestlings in the nests were used in the experiment. Nestlings were put in a $10^{\circ} \mathrm{C}$ cooler for $10 \mathrm{~min}$. Initial $\left(T_{\mathrm{i}}\right)$ and final $\left(T_{\mathrm{f}}\right)$ body temperatures during the cold stress were taken by inserting a thermal probe (Omega $\mathrm{Cu}-\mathrm{Ni}$, $\mathrm{T}$ type, 36 gauge) into the cloaca, and temperatures were read with a thermometer (Omega HH506A, resolution: $\left.0.1^{\circ} \mathrm{C}\right)$. The temperature $\left(T_{\mathrm{a}}\right)$ of the cooler was the average of temperatures measured in the cooler every $10 \mathrm{~s}$ during the 10-min test. The homeothermic index was calculated as $\left(T_{\mathrm{f}}-T_{\mathrm{a}}\right) /\left(T_{\mathrm{i}}-T_{\mathrm{a}}\right)$ (Ricklefs 1987), which ranges from 0 to 1 . We then estimated the age of endothermy by fitting the $H$ data as a logistic curve as in growth data. The age of endothermy was calculated as the age in days when $H$ achieved 0.9 .

\section{Data Analysis}

Daily nest predation rates during the nestling period were estimated using the Mayfield method (Mayfield 1961) and based on data for the same populations during 1988-2005 (Martin et al. 2007). General linear models were used to test the ability of foraging mode (aerial, ground, and arboreal) as a factor and nest predation rates and adult mass as covariates to explain variation in developmental variables of interest. Adult mass was also included as a covariate to control for any scaling effects on growth rates (Martin et al. 2011; Remes and Martin 2002) and was $\log _{10}$ transformed to achieve a normal distribution. Full models that included nest predation, foraging mode, and logtransformed adult mass were tested initially, and then individual terms were dropped stepwise in a backward procedure when they were not significant.

We first examined the relationships of nest predation, foraging mode, and adult mass with growth rates $(K)$ of mass, tarsus, and wing chord. We also investigated whether species prioritized growth of locomotor components by increasing growth rates of tarsus or wing chord relatively more than that of body mass as a function of nest predation or foraging mode. Growth rates of tarsus or wing chord length were divided by growth rates of mass as a measure of relative rates of growth of locomotor components versus body mass for comparisons among species. We also examined the relative prioritization of growth of locomotor components by estimating the proportion of adult size that wing chords and tarsi achieved at the age when species reached $70 \%$ of adult mass (fig. 1). We chose $70 \%$ for mass, because offspring of all study species reached $70 \%$ of adult mass before fledging, and this then allowed standardization across species. We also examined the proportion of adult size achieved at fledging in mass, tarsus length, and wing chord length. Adult mass, tarsus length, and wing chord length were means for species based on large sample sizes from long-term banding data collected at the field site since 1993 (table A1 in the online edition of the American Naturalist, T. E. Martin, unpublished data). These proportional data were arcsine transformed.

We used linear regression to examine potential influences on age of endothermy. To investigate whether species prioritized development of endothermy over growth of mass, we tested for a relationship between nest predation rates and the proportion of adult mass expressed when offspring of each species achieved endothermy (i.e., homeothermic index $=0.9$ ). We included adult mass as an explanatory variable in the regression analysis because larger species generally achieve endothermy at a relatively smaller mass (Dunn 1975). We found that foraging mode was not significant (data not shown) in explaining differential development of endothermy, and it was not included in models reported here.

We also analyzed the data using independent contrasts to control for potential phylogenetic influences using the software package Phylip 3.68 (Felsenstein 1985). We first constructed a working phylogeny based on a published supertree of passerine birds (Barker et al. 2004; Jønsson and Fjeldså 2006). We assumed equal branch lengths in the phylogeny and analyzed independent contrasts in linear regression where regressions were forced through the origin (Garland et al. 1992).

\section{Results}

\section{Growth Rates}

Growth rates of offspring mass increased with nest predation rates, and residual variation was not explained by foraging mode or adult mass (nest predation: fig. $2 A$; foraging mode: NS; adult mass: NS). Growth rates of wing chords increased with nest predation rates even more strongly, and residual variation was still unexplained by 


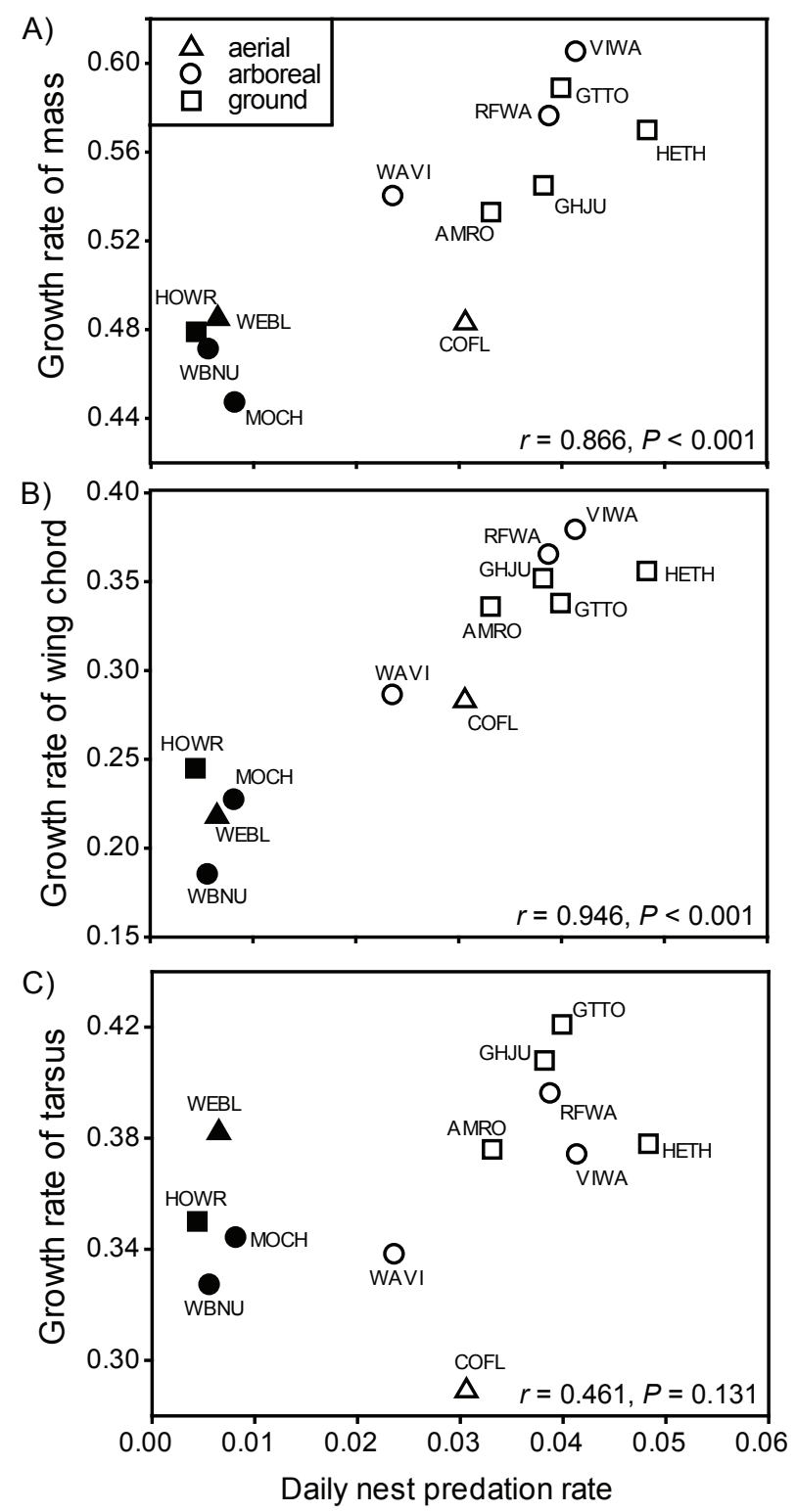

Figure 2: Growth rates $(K)$ of body mass $(A)$, wing chord $(B)$, and tarsus $(C)$ in relation to daily nest predation rates for 12 altricial species (for species codes, see table 1). Species were symbolized on the basis of their foraging modes and nesting sites (open symbol: open cup nester; filled symbol: cavity nester).

foraging behavior (nest predation: fig. $2 B$; foraging mode: NS; adult mass: NS). In contrast, growth rates of tarsi were not related to predation risk, foraging mode, or adult mass (fig. 2C; foraging mode: NS; adult mass: NS). Analyses of phylogenetically independent contrasts showed the same patterns for all three traits (table 2).

\section{Relative Growth among Morphological Traits}

Species with higher nest predation rates showed higher relative growth rates of wing chords to mass that was not further explained by foraging mode (nest predation: fig. $3 A$; foraging mode: NS; adult mass: NS). In contrast, relative growth rate of tarsus to mass did not vary with nest predation or foraging behavior (fig. $3 B$; foraging mode: NS; adult mass: NS). Independent contrast analyses yielded the same results, except growth rates of tarsus relative to mass decreased with increased predation risk (table 2), which indicated that increased nest predation risk did not favor prioritized growth of tarsi over mass.

Offspring of species with higher nest predation rates 
Table 2: Regression analysis of growth and development variables in relation to nest predation rates, foraging modes, and adult mass when controlled for phylogenetic effects through independent contrast analyses (Felsenstein 1985)

\begin{tabular}{|c|c|c|c|c|c|c|c|c|}
\hline \multirow[b]{2}{*}{ Variable } & \multicolumn{2}{|c|}{$\begin{array}{c}\text { Nest } \\
\text { predation }\end{array}$} & \multicolumn{2}{|c|}{$\begin{array}{l}\text { Foraging } \\
\text { mode }\end{array}$} & \multicolumn{2}{|c|}{$\begin{array}{c}\text { Growth } \\
\text { rate of } \\
\text { mass }\end{array}$} & \multicolumn{2}{|c|}{$\begin{array}{c}\text { Adult } \\
\text { body mass }\end{array}$} \\
\hline & $F$ & $P$ & $F$ & $P$ & $F$ & $P$ & $F$ & $P$ \\
\hline Growth rate of mass & 17.4 & .002 & $\ldots$ & NS & $\ldots$ & $\ldots$ & $\cdots$ & NS \\
\hline Growth rate of tarsus & $\ldots$ & NS & $\ldots$ & NS & $\ldots$ & $\ldots$ & $\ldots$ & NS \\
\hline Growth rate of wing chord & 34.8 & $<.001$ & $\ldots$ & NS & $\ldots$ & $\ldots$ & $\ldots$ & NS \\
\hline Ratio of growth rate of wing chord to mass & 10.0 & .01 & $\ldots$ & NS & $\ldots$ & $\ldots$ & $\ldots$ & NS \\
\hline Ratio of growth rate of tarsus to mass & 7.7 & .02 & $\cdots$ & NS & $\ldots$ & $\ldots$ & $\ldots$ & NS \\
\hline Proportion of adult wing chord at $70 \%$ of adult mass & 27.8 & .001 & 11.1 & .005 & $\ldots$ & $\ldots$ & $\ldots$ & NS \\
\hline Proportion of adult tarsus at $70 \%$ of adult mass & $\ldots$ & NS & $\ldots$ & NS & $\ldots$ & $\ldots$ & $\ldots$ & NS \\
\hline Proportion of wing chord at fledging & 6.6 & .028 & $\ldots$ & NS & $\ldots$ & $\ldots$ & $\ldots$ & NS \\
\hline Proportion of mass at fledging & 9.1 & .017 & 3.8 & .070 & $\ldots$ & $\ldots$ & $\ldots$ & NS \\
\hline Age of endothermy ${ }^{\mathrm{a}}$ & 9.2 & .013 & $\cdots$ & $\ldots$ & 7.8 & .019 & $\ldots$ & NS \\
\hline Proportion of adult mass at age of endothermy & 6.2 & .034 & $\ldots$ & $\ldots$ & $\ldots$ & $\ldots$ & 8.1 & .019 \\
\hline
\end{tabular}

${ }^{a}$ Simple regression.

reached a greater proportion of adult wing chord length at the age when they achieved $70 \%$ of adult mass, and foraging mode explained some residual variation (fig. $3 C$; nest predation: $F_{1,8}=17.2, P=.003$; foraging mode: $F_{2,8}=5.6$, $P=.03$; adult mass: NS; table 2). Ground-foraging birds achieved proportionately larger wings for their nest predation rate than other foraging modes (fig. $3 C$ ). The relative size of tarsi when offspring reached $70 \%$ of adult mass was not related to nest predation risk or foraging mode, but it was related to adult mass (fig. $3 D$; nest predation: NS; foraging mode: NS; adult mass: $\left.F_{1,10}=13.8, P=.004\right)$. However, even adult mass effects disappeared in the analyses of independent contrast (table 2).

Although offspring of species with higher nest predation risk achieved larger relative wing sizes for a constant relative body size (fig. 3C), they still fledged at smaller relative wing sizes (fig. $3 E$ ). Adult mass and foraging mode did not explain any further variation in relative wing size at fledging (foraging mode: NS; adult mass: NS; table 2). All species fledged before wings reached adult size (fig. $3 E$ ). Offspring also fledged at lower relative body mass in species with higher nest predation risk (fig. $3 F$ ) and that were of larger adult mass (nest predation: $F_{1,9}=13.4, P=$ .005 ; foraging mode: NS; adult mass: $F_{2,9}=12.5, P=$ .006). Note that the species with the lowest predation risk fledged at larger masses than adults, reflecting excess fat reserves, whereas species with high predation risk fledged at masses still smaller than adults (fig. $3 F$ ). Analyses of independent contrasts also showed an effect of nest predation risk on relative mass at fledging, whereas the effect of adult mass disappeared and foraging mode became marginally significant (table 2). We did not analyze relative tarsus size at fledging, because all species achieved adult size by the time they fledged.

\section{Age of Endothermy}

Endothermy was achieved earlier in species with faster growth rates of mass (fig. 4A), as found previously (Dunn 1975). However, growth rates were strongly related to nest predation rates (fig. $2 A$ ) and when both growth rate of mass and nest predation were included in the same model, growth rate no longer explained variation in the age of endothermy, whereas nest predation did (growth rate of mass: $r_{\mathrm{p}}=-0.14, P=.68$; nest predation: $r_{\mathrm{p}}=-0.60$, $P=.05 ; \mathrm{df}=9$ ). Exclusion of the nonsignificant growth rate of mass yielded an even stronger correlation between nest predation alone and age of endothermy (fig. 4B). Age of endothermy was marginally related to nest predation, and adult mass became significant when restricted to opennesting species alone (nest predation risk: $r_{\mathrm{p}}=-0.72$, $P=.066$; adult mass: $r_{\mathrm{p}}=-0.81, P=.029 ; \mathrm{df}=5$ ). When all species were included, species with higher nest predation rates achieved endothermy at relatively smaller mass, even after controlling for the fact that larger species achieved endothermy at relatively smaller mass (fig. $4 C$, $4 D$; adult mass: $r_{\mathrm{p}}=-0.80, P=.003$; nest predation: $\left.r_{\mathrm{p}}=-0.83, P=.002 ; \mathrm{df}=9\right)$. When open-nesting species were considered alone, nest predation did not explain variation, although larger species still achieved 


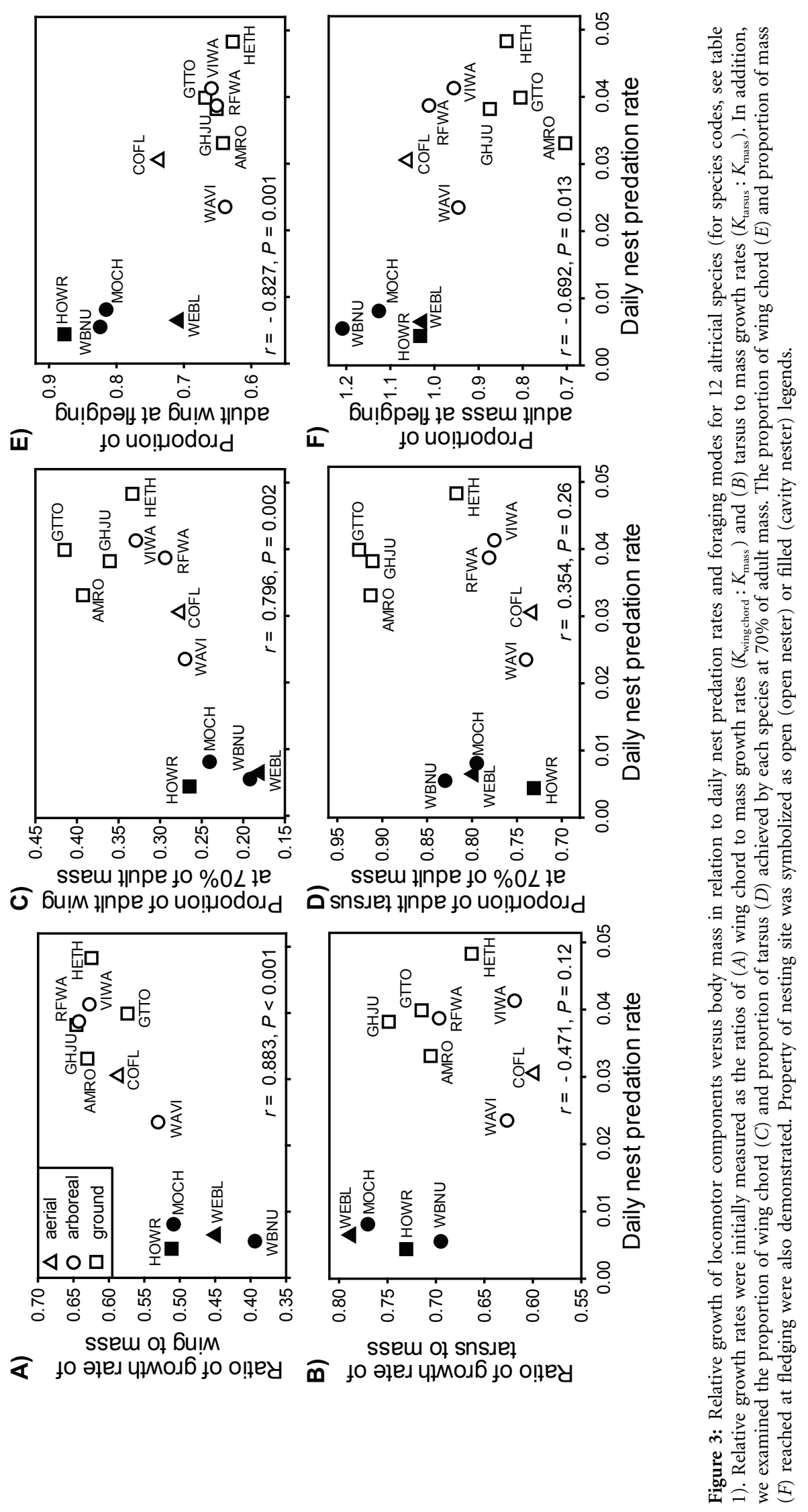



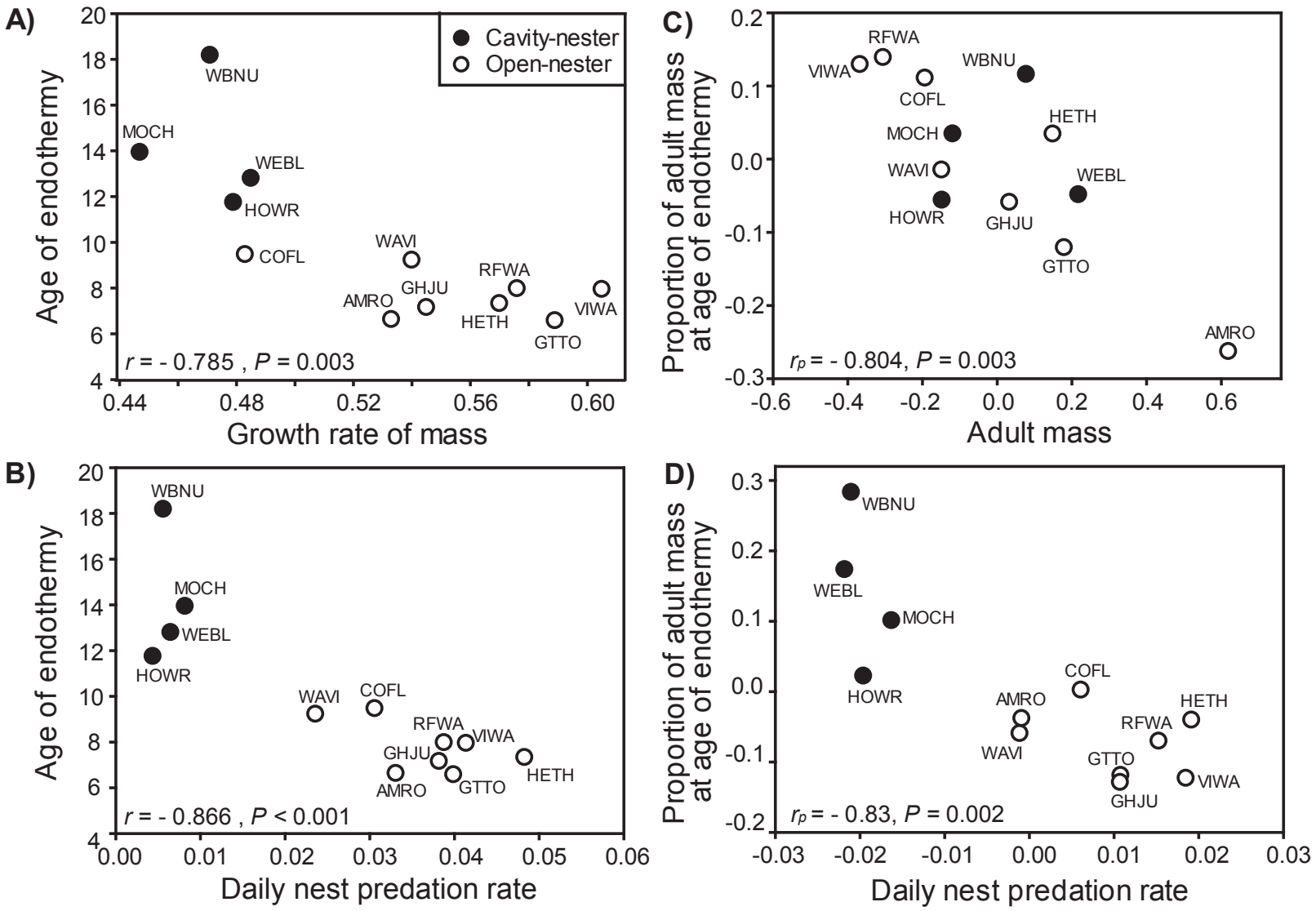

Figure 4: Development of endothermy with respect to nest predation risk and mass growth in 12 altricial species (for species codes, see table 1). Age at which endothermy was achieved was earlier in species with higher growth rates of mass $(A)$ and daily nest predation rates $(B)$. Proportion of adult mass that was achieved at age of endothermy was smaller in species with larger adult mass controlled for nest predation rates $(C)$ and higher daily nest predation rates controlled for adult mass $(D)$ using partial regression analysis.

endothermy at relatively smaller mass (adult mass: $r_{\mathrm{p}}=-0.95, P<.001$; nest predation: $r_{\mathrm{p}}=-0.37, P=$ .42 ; $\mathrm{df}=5$ ). These relationships were the same when controlling for possible phylogenetic effects using independent contrasts (table 2).

\section{Discussion}

An association between nest predation risk and growth rate of mass among passerine species has been described previously (Bosque and Bosque 1995; Remes and Martin 2002; Martin et al. 2011), but the responses of individual body components that can facilitate escape are unstudied with respect to nest predation risk across species. Growth and development comprise multiple semiautonomous units that may compete for resources, such that growth of some traits may constrain growth rates of other traits (Ricklefs 1968, 1973, 1979; Sacher and Staffeld 1974; McClure and Randolph 1980; Nijhout and Emlen 1998). In- deed, although growth rates of mass and wing length as well as development rates of endothermy all increased with nest predation risk across species, the relative increase in growth rates was not uniform among these traits. Growth rates of wings increased faster than growth rates of mass (fig. 3A) that were associated with higher predation risk. Moreover, species with higher predation risk fledged earlier at relatively smaller mass but achieved larger relative sizes of wings at a constant relative mass (fig. $3 C$ ), which suggests that greater predation risk favors a strategy of prioritizing wing growth over mass. These results fit well with a recent experimental study that showed that predation risk can shift prioritization of wing growth versus mass within a single species (Coslovsky and Richner 2011), which verifies the role that nest predation can play. This prioritization may be particularly critical in species at higher risk of predation, because they fledge from the nest at relatively younger ages (Remes and Martin 2002; Roff et al. 2005), which also causes them to fledge at smaller 
relative wing sizes (fig. 3E). Partially developed wings can still yield significant performance function that can help them escape predators, but the performance advantage increases with relative wing size (Dial 2003; Dial et al. 2006, 2008; Jackson et al. 2009; Dial and Jackson 2010). Thus, achieving the largest relative size possible at early ages (fig. 3C) may be critical for those species that are at high risk and need to leave the nest at early ages.

Thermoregulatory independence is also critical for altricial young to survive after leaving their nests. Thermoregulation is energetically costly and can constrain overall growth rates (McClure and Randolph 1980; Olson 1992; Starck and Ricklefs 1998), such that growth rate of mass and development of endothermy might be negatively related. Yet previous studies found a positive relationship between growth rates of mass and development of endothermy (Dawson and Evans 1960; Dunn 1975). This covariance may in part result from the fact that, as we show, both growth rate of mass and age of endothermy are related to nest predation risk (figs. $2 A, 4 B$ ). Moreover, we found that species with higher nest predation risk achieved endothermy at relatively smaller mass even after controlling for adult mass (fig. 4D). Development of endothermy at relatively smaller mass might be achieved by earlier maturation of muscular, neural, and hormone systems (Starck and Ricklefs 1998; Olson et al. 1999; Marjoniemi 2001). Nonetheless, these results suggest that greater nest predation risk favors prioritization of resources to earlier development of endothermy to achieve thermoregulation even at smaller fledging mass. Thus, our results for both wing chords and endothermy support the hypothesis that nest predation risk can favor prioritization of traits that facilitate escape from risky nest environments.

Cavity-nesting species might differ from open-nesting species in development of endothermy because of differences in the microclimates of these two nest types. The temperature in occupied cavities is not warmer, on average, but it is less variable than the temperature of the air around open nests (Martin and Ghalambor 1999). If the more stable temperature of cavities reduces thermoregulatory costs, we might expect nestlings to have more energy to grow or develop endothermy earlier, in contrast with our results. On the other hand, the cool average temperature of cavities (Martin and Ghalambor 1999) should not favor delayed onset of endothermy. Instead, the clear evolutionary differences in nest predation risk between these nest types (Martin and Li 1992; Martin 1995; Fontaine et al. 2007) provide a more parsimonious explanation for the variation in rates of development of endothermy (fig. 4). However, we did not find the relationship between nest predation and development of endothermy when examining open nesting species alone. Still, power was low, with only eight species, and clear conclusions will not be possible until more species are studied.

Nest predation apparently was not a critical factor influencing growth rate of tarsi. Fast growth of tarsi might be important for reasons independent of nest predation. For example, altricial young compete for food from parents by begging before leaving nests (O'Connor 1984), and taller young often obtain more food (Kilner 1995). Consequently, tarsus growth rate may be related to parental feeding strategies and sibling competition. Ultimately, tarsus growth was not strongly related to nest predation risk, and all species instead achieved adult size of their tarsus by the time that they fledged.

Finally, we only examined the possible influence of foraging behavior on trait prioritization in a coarse way by examining three clearly different foraging modes. Yet even among these very different foraging modes, little variation in trait prioritization was explained, which tentatively suggests that foraging behavior is less important than nest predation in driving rate of development of locomotor traits.

Understanding variation in differential growth trajectories of body components among species can help advance our knowledge of the evolution of growth strategies. Our study suggests that nest predation risk can affect not only overall growth rates but also relative prioritization of growth of body components. The faster relative rates of growth and development of wings and endothermy, compared with that of body mass, suggest that traits that facilitate escape and independent living outside the nest are prioritized in species with a higher risk of nest predation. Yet compared with low-risk species, species that are at higher risk still leave the nest (i.e., fledge) at smaller relative sizes of mass and wings, which demonstrates the importance of prioritization; without prioritization, relative sizes would be further compromised and inhibit early fledging in high-risk species. Future studies of locomotor performance associated with ontogenetic change can provide new insights into the costs and benefits of differential growth strategies.

\section{Acknowledgments}

We thank D. Emlen, B. Jackson, J. Maron, and A. Woods for comments on earlier versions of this article. This work was supported by the U.S. Geological Survey Climate Change Research Program, the National Science Foundation (grants DEB-0543178 and DEB-0841764 to T.E.M.), and the National Research Initiative of the U.S. Department of Agriculture Cooperative State Research, Education and Extension Service (grant 2005-02817). Any use of trade, product, or firm names is for descriptive purposes 
only and does not imply endorsement by the U.S. government.

Proceedings of the Royal Society B: Biological Sciences 276:34573466.

$\rightarrow$ Jønsson, K. A., and J. Fjeldså. 2006. A phylogenetic supertree of oscine passerine birds (Aves: Passeri). Zoologica Scripta 35:149-186.

Literature Cited

Arendt, J. D. 1997. Adaptive intrinsic growth rates: an integration across taxa. Quarterly Review of Biology 72:149-177.

$\rightarrow$ - 2003. Reduced burst speed is a cost of rapid growth in anuran tadpoles: problems of autocorrelation and inferences about growth rates. Functional Ecololgy 17: 328-334.

$\rightarrow$ Austin, G. T., and R. E. Ricklefs. 1977. Growth and development of the rufous-winged sparrow (Aimophila carpalis). Condor 79:37-50.

$\rightarrow$ Barker, F. K., A. Cibois, P. Schikler, J. Feinstein, and J. Cracraft. 2004. Phylogeny and diversification of the largest avian radiation. Proceedings of the National Academy of Sciences of the USA 101: 11040-11045.

$\rightarrow$ Bennett, A. F. and J. A. Ruben. 1979. Endothermy and activity in vertebrates. Science 206:649-654.

$\rightarrow$ Billerbeck, J. M., T. E. Lankford Jr., and D. O. Conover. 2001. Evolution of intrinsic growth and energy acquisition rates. I. Trade offs with swimming performance in Menidia menidia. Evolution 55:1863-1872.

$\rightarrow$ Bosque, C., and M. T. Bosque. 1995. Nest predation as a selective factor in the evolution of developmental rates in altricial birds. American Naturalist 145:234-260.

$\rightarrow$ Case, T. J. 1978. On the evolution and adaptive significance of post $\rightarrow$ natal growth rates in the terrestrial vertebrates. Quarterly Review of Biology 53:243-282.

$\rightarrow$ Coslovsky, M., and H. Richner. 2011. Predation risk affects offsprin $\rightarrow$ growth via maternal effects. Functional Ecology 25:878-888.

$\rightarrow$ Dawson, W. R., and F. C. Evans. 1960. Relation of growth and development to temperature regulation in nestling vesper sparrows $\rightarrow$ Condor 62:329-340.

$\rightarrow$ Dial, K. P. 2003. Evolution of avian locomotion: correlates of fligh style, locomotor modules, nesting biology, body size, development, and the origin of flapping flight. Auk 120:941-952.

Dial, K. P., and B. E. Jackson. 2010. When hatchlings outperform adults: locomotor development in Australian brush turkeys (Alectura lathami, Galliformes). Proceedings of the Royal Society BBiological Sciences, doi:10.1098/rspb.2010.1984.

$\rightarrow$ Dial, K. P., B. E. Jackson, and P. Segre. 2008. A fundamental avian wing-stroke provides a new perspective on the evolution of flight. Nature 451:985-989.

$\rightarrow$ Dial, K. P., R. J. Randall, and T. R. Dial. 2006. What use is half a wing in the ecology and evolution of birds? BioScience 56:437-445.

$\rightarrow$ Dunn, E. H. 1975. The timing of endothermy in the development of altricial birds. Condor 77:288-293.

$\rightarrow$ Felsenstein, J. 1985. Phylogenies and the comparative method. American Naturalist 125:1-15.

$\rightarrow$ Fontaine, J. J., M. Martel, H. A. Markland, A. A. Niklison, K. L. Decker, and T. E. Martin. 2007. Testing ecological and behavioral correlates of nest predation. Oikos 116:1887-1894.

$\rightarrow$ Garland, J. T., P. H. Harvey, and A. R. Ives. 1992. Procedures for the analysis of comparative data using phylogenetically independen $\rightarrow$ contrasts. Systematic Biology 41:18-32.

$\rightarrow$ Jackson, B. E., P. Segre, and K. P. Dial. 2009. Precocial development of locomotor performance in a ground-dwelling bird (Alectori chukar): negotiating a three-dimensional terrestrial environment. $\rightarrow$ Kilner, R. 1995. When do canary parents respond to nestling signals of need? Proceedings of the Royal Society B: Biological Sciences 260:343-348.

Klingenberg, C. P. 1998. Heterochrony and allometry: the analysis of evolutionary change in ontogeny. Biological Reviews 73:79-123.

Lindström, J. 1999. Early development and fitness in birds and mammals. Trends in Ecology \& Evolution 14:343-348.

Marjoniemi, K. 2001. Thermogenic mechanisms during the development of endothermy in juvenile birds. PhD diss. University of Oulu, Oulu, HI.

Martin, T. E. 1992. Breeding productivity considerations: what are the appropriate habitat features for management? Pages 455-473 in J. M. Hagan and D. W. Johnston, eds. Ecology and conservation of Neotropical migrants. Smithsonian Institution, Washington, DC.

$\rightarrow-$ 1995. Avian life history evolution in relation to nest sites, nest predation and food. Ecological Monographs 65:101-127.

$\rightarrow-2007$. Climate correlates of 20 years of trophic changes in a high-elevation riparian system. Ecology 88:367-380.

$\rightarrow$ Martin, T. E., S. K. Auer, R. D. Bassar, A. M. N. Niklison, and P. Lloyd. 2007. Geographic variation in avian incubation periods and parental influences on embryonic temperature. Evolution 61:25582569.

Martin, T. E., and G. R. Geupel. 1993. Nest-monitoring plots: methods for locating nests and monitoring success. Journal of Field Ornithology 64:507-519.

Martin, T. E., and C. K. Ghalambor. 1999. Males feeding females during incubation. I. Required by microclimate or constrained by nest predation? American Naturalist 153:131-139.

Martin, T. E., and P. Li. 1992. Life history traits of open- vs. cavitynesting birds. Ecology 73:579-592.

Martin, T. E., P. Lloyd, C. Bosque, D. Barton, L. Biancucci, Y. Cheng, and R. Ton. 2011. Growth rate variation among passerine species in temperate and tropical sites: an antagonistic interaction between parental food provisioning and nest predation risk. Evolution 65: $1607-1622$

$\rightarrow$ Mayfield, H. 1961. Nesting success calculated from exposure. Wilson Bulletin 73:255-261.

McClure, P. A., and J. C. Randolph. 1980. Relative allocation of energy to growth and development of homeothermy in the eastern wood rat (Neotoma floridana) and hispid cotton rat (Sigmodon hispidus). Ecological Monographs:199-219.

$\rightarrow$ Nijhout, H. F., and D. J. Emlen. 1998. Competition among body parts in the development and evolution of insect morphology. Proceedings of the National Academy of Sciences of the USA 95: 3685-3689.

$\rightarrow$ O'Connor, R. J. 1977. Differential growth and body composition in altricial passerines. Ibis 119:147-166.

O'Connor, R. J. 1984. The growth and development of birds. Wiley, London.

Olson, J. M. 1992. Growth, the development of endothermy, and the allocation of energy in red-winged blackbirds (Agelaius phoeniceus) during the nestling period. Physiological Zoology 65:124-152.

Olson, J. M., F. M. A. McNabb, M. S. Jablonski, and D. V. Ferris. 1999. Thyroid development in relation to the development of en- 
dothermy in the red-winged blackbird (Agelaius phoeniceus). General and Comparative Endocrinology 116:204-212.

Remes̊, V., and T. E. Martin. 2002. Environmental influences on the $\rightarrow$ R evolution of growth and developmental rates in passerines. Evolution 56:2505-2518.

$\rightarrow$ Ricklefs, R. E. 1968. Patterns of growth in birds. Ibis 110:419-451. $\rightarrow$ . 1973. Patterns of growth in birds. II. Growth rate and mode of development. Ibis 115:117-201.

$\rightarrow$. 1979. Adaptation, constraint, and compromise in avian postnatal development. Biological Reviews of the Cambridge Philosophical Society 54:269-290.

$\rightarrow-$ 1987. Characterizing the development of homeothermy by rate of body cooling. Functional Ecology 1:151-157.
Roff, D. A. 1992. The evolution of life histories. Chapman \& Hall, New York.

Roff, D. A., V. Remes, and T. E. Martin. 2005. The evolution of fledging age in songbirds. Journal of Evolutionary Biology 18: 1425-1433.

Sacher, G. A., and E. F. Staffeld. 1974. Relation of gestation time to brain weight for placental mammals: implications for theory of vertebrate growth. American Naturalist 108:593-615.

Starck, J. M., and R. E. Ricklefs. 1998. Avian growth and development. Oxford University Press, New York.

Associate Editor: Anna Qvarnström Editor: Ruth G. Shaw
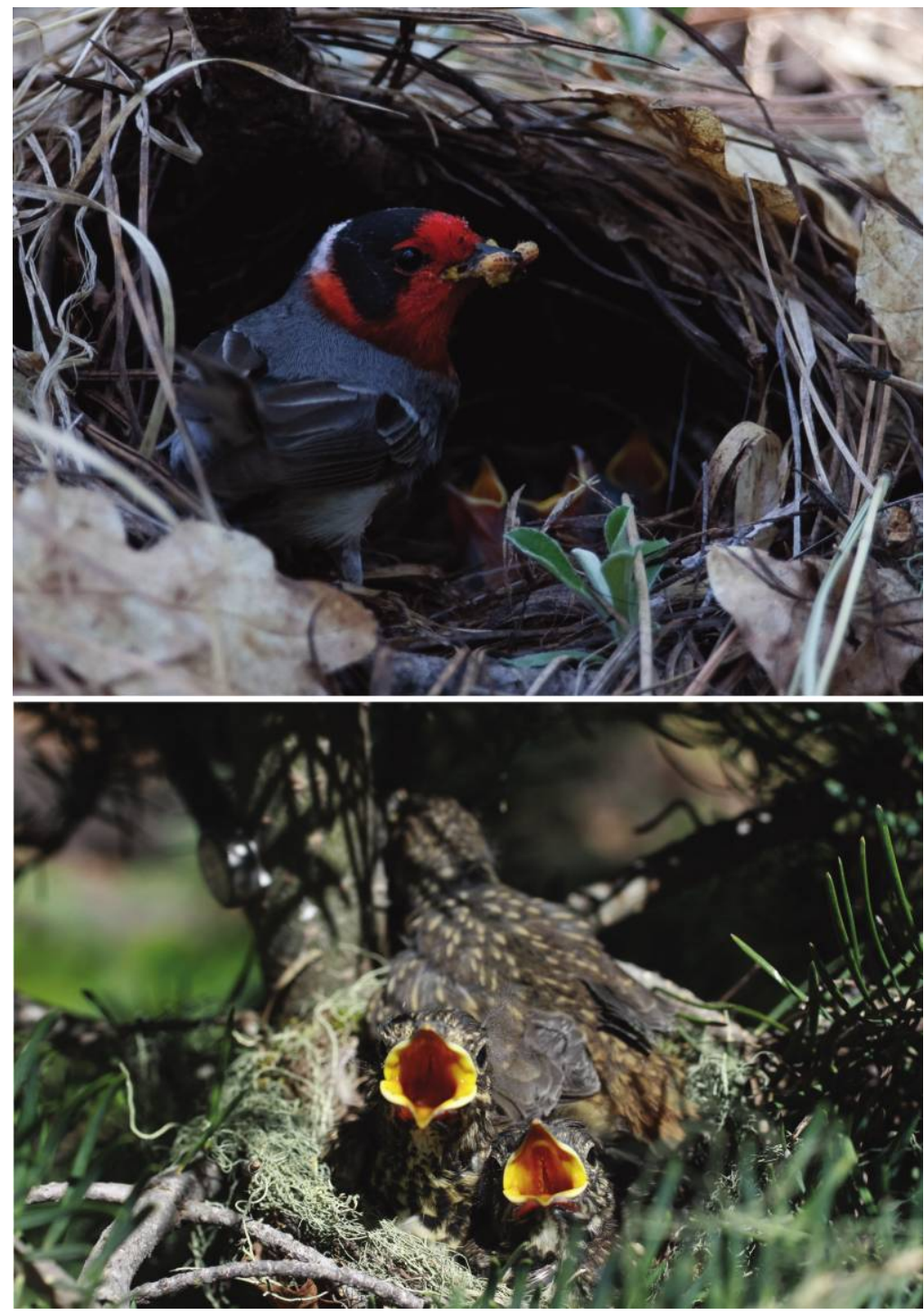

Baby birds of the red-faced warbler (Cardellina rubrifrons) are vulnerable to predators (top). They need food and warmth from parents until they can leave the nest. Hermit thrush (Catharus guttatus) experience higher nest predation risk and develop wings and endothermy faster (bottom). Top photograph by Thomas E. Martin; bottom photograph by Yi-Ru Cheng. 